\title{
A new modification of the quasi-newton method for unconstrained optimization
}

\author{
Hamsa Th. Saeed Chilmeran', Huda I. Ahmed ${ }^{2}$, Eman T. Hamed ${ }^{3}$, Abbas Y. Al-Bayati ${ }^{4}$ \\ ${ }^{1}$ Department of Mathematics, College of Computers Sciences and Mathematics, University of Mosul, Iraq \\ ${ }^{2,3}$ Department of Operation Researches and Intelligent Techniques, College of Computers Sciences and Mathematics, \\ University of Mosul, Iraq \\ ${ }^{4}$ University of Telafer, Tall'Afar, Iraq
}

\begin{tabular}{|c|c|}
\hline Article Info & ABSTRACT \\
\hline Article history: & In this work we propose and analyze a hybrid conjugate gradient (CG) \\
\hline $\begin{array}{l}\text { Received Apr 30, } 2020 \\
\text { Revised Aug 11, } 2020 \\
\text { Accepted Oct 1, } 2020\end{array}$ & $\begin{array}{l}\text { method in which the parameter } \beta_{k} \text { is computed as a linear combination } \\
\text { between Hager-Zhang [HZ] and Dai-Liao [DL] parameters. We use this } \\
\text { proposed method to modify BFGS method and to prove the positive } \\
\text { definiteness and QN-conditions of the matrix. Theoretical trils confirm that }\end{array}$ \\
\hline $\begin{array}{l}\text { Keywords: } \\
\text { BFGS method } \\
\text { Conjugate graient method }\end{array}$ & $\begin{array}{l}\text { well as, the new search directions areglobally convergent using strong Wolfe } \\
\text { conditions. The numerical experiments show that the proposed method is } \\
\text { promising and outperforms alternative similar CG-methods using Dolan- } \\
\text { Mor'e performance profile". }\end{array}$ \\
\hline
\end{tabular}

This is an open access article under the CC BY-SA license.

Globally convergence

Strong wolfe condition

Unconstrainedoptimization

Convex function

\begin{abstract}
In this work we propose and analyze a hybrid conjugate gradient $(\mathrm{CG})$ method in which the parameter $\beta_{k}$ is computed as a linear combination roposed method definiteness and QN-conditions of the matrix. Theoretical trils confirm that the new search directions aredescent directions under some conditions, as conditions. The numerical experiments show that the proposed method is Mor'e performance profile".
\end{abstract}

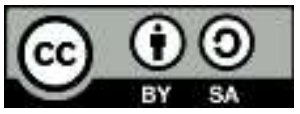

\section{Corresponding Author:}

Huda Isaam Ahmed

Department of Operation Researches and Intelligent Techniques

College of Computers Sciences and Mathematics

University of Mosul, Iraq

Email: hudaea72@gmail.com

\section{INTRODUCTION}

The conjugate gradient (CG) method is an efficient and organized tool for solving the large-scale nonlinear optimization problem, due to its simplicity, easiness, and low memory requirements. This method is very popular for mathematician and engineers and those who are interested in solving the large-scale optimization problems. The nonlinear unconstrained optimization.

$$
\underset{\mathrm{x} \in \mathrm{R}^{\mathrm{n}}}{\operatorname{minimize}} f(x)
$$

where $f(x): R^{n} \rightarrow R$ is smooth function bounded from below, generates a sequence of points as formula :

$$
x_{k+1}=x_{k}+\alpha_{k} d_{k}
$$

where $\alpha_{k}$ is a optimal step computed by line search and $d_{k}$ are generated as : 


$$
d_{k+1}=-g_{k+1} ; \mathrm{k}=0 \text { and } \quad d_{k+1}=-g_{k+1}+\beta_{k} d_{k} ; \quad \text { for } \mathrm{k} \geq 1
$$

In (3), $\beta_{\mathrm{k}} \in \mathrm{R}$ is known as conjugacy coefficient. There are different CG- methods correspond to different choices for the $\beta_{\mathrm{k}}$, such as (HS) method [1], FR method [2], PRP method [3, 4] and DY method [5], Also Dai-Liao [6]. Considered the following formula:

$$
\beta_{k}^{D L}=\frac{\mathrm{g}_{\mathrm{k}+1}^{\mathrm{T}} y_{k}}{d_{k}^{T} y_{k}}-t \frac{\mathrm{g}_{\mathrm{k}+1}^{\mathrm{T}} s_{k}}{d_{k}^{T} y_{k}}, \mathrm{t}>0
$$

Where $y_{k}=g_{k+1}-g_{k}$. As Hager-Zhang [7] proposed the formula:

$$
\beta_{k}^{N}=\frac{\mathrm{g}_{\mathrm{k}+1}^{\mathrm{T}} y_{k}}{d_{k}^{T} y_{k}}-2 \frac{\left\|\mathrm{y}_{\mathrm{k}}\right\|^{2}}{d_{k}^{T} y_{k}} \frac{\mathrm{g}_{\mathrm{k}+1}^{\mathrm{T}} d_{k}}{d_{k}^{T} y_{k}}
$$

where $\|\cdot\|$ denotes the Euclidean norm. And the author introduced a parameter $t_{k}$ in (5), yielding:

$$
\beta_{k}^{H Z}=\frac{\mathrm{g}_{\mathrm{k}+1}^{\mathrm{T}} y_{k}}{d_{k}^{T} y_{k}}-t \frac{\left\|y_{k}\right\|^{2}}{d_{k}^{T} y_{k}} \frac{\mathrm{g}_{\mathrm{k}+1}^{\mathrm{T}} d_{k}}{d_{k}^{T} y_{k}}
$$

Note that when $t_{k}=2$ (6) reduce to (5). For more details see [8]. Many authors are studied the convergence of the on top of formulas for years [9-15]. The line search in the CG-algorithmsoften is based on the standard Wolfe conditions:

$$
\begin{aligned}
& f\left(x_{k}+\alpha_{k} d_{k}\right)-f\left(x_{k}\right) \leq \delta \alpha_{k} \nabla f\left(x_{k}\right)^{T} d_{k} \\
& g_{k+1}^{T} d_{k} \geq \sigma \nabla f\left(x_{k}\right)^{T} d_{k}
\end{aligned}
$$

The constants are within the period $0<\delta<\sigma<1$, for additional details is found in [16,17]

\section{DERIVATION OF A NEW PARAMETER}

We have to drive a parameter ${ }^{\beta_{k}}$ which is incorporation between (4) and (6),

$$
\begin{aligned}
& \beta_{k}^{\text {new }}=\varpi_{k}\left(\frac{\mathrm{g}_{\mathrm{k}+1}^{\mathrm{T}} y_{k}}{d_{k}^{T} y_{k}}-t \frac{\mathrm{g}_{\mathrm{k}+1}^{\mathrm{T}} s_{k}}{d_{k}^{T} y_{k}}\right)+\left(1-\varpi_{k}\right)\left(\frac{\mathrm{g}_{\mathrm{k}+1}^{\mathrm{T}} y_{k}}{d_{k}^{T} y_{k}}-t \frac{\left\|\mathrm{y}_{\mathrm{k}}\right\|^{2} \mathrm{~g}_{\mathrm{k}+1}^{\mathrm{T}} d_{k}}{d_{k}^{T} y_{k}}\right) \\
& \beta_{k}^{\text {new }}=\varpi_{k} \frac{\mathrm{g}_{\mathrm{k}+1}^{\mathrm{T}} y_{k}}{d_{k}^{T} y_{k}}-\varpi_{k} t \frac{\mathrm{g}_{\mathrm{k}+1}^{\mathrm{T}} s_{k}}{d_{k}^{T} y_{k}}+\frac{\mathrm{g}_{\mathrm{k}+1}^{\mathrm{T}} y_{k}}{d_{k}^{T} y_{k}}-t \frac{\left\|\mathrm{y}_{\mathrm{k}}\right\|^{2}}{d_{k}^{T} y_{k}} \frac{\mathrm{g}_{\mathrm{k}+1}^{\mathrm{T}} d_{k}}{d_{k}^{T} y_{k}}-\varpi_{k} \frac{\mathrm{g}_{\mathrm{k}+1}^{\mathrm{T}} y_{k}}{d_{k}^{T} y_{k}}+t \varpi_{k}\left(\frac{\left\|\mathrm{y}_{\mathrm{k}}\right\|^{2}}{d_{k}^{T} y_{k}} \frac{\mathrm{g}_{\mathrm{k}+1}^{\mathrm{T}} d_{k}}{d_{k}^{T} y_{k}}\right) \\
& \beta_{k}^{\text {new }}=\frac{\mathrm{g}_{\mathrm{k}+1}^{\mathrm{T}} y_{k}}{d_{k}^{T} y_{k}}-\varpi_{k} t \frac{\mathrm{g}_{\mathrm{k}+1}^{\mathrm{T}} s_{k}}{d_{k}^{T} y_{k}}-\left(1-\varpi_{k}\right) t \frac{\left\|\mathrm{y}_{\mathrm{k}}\right\|^{2}}{d_{k}^{T} y_{k}} \frac{\mathrm{g}_{\mathrm{k}+1}^{\mathrm{T}} d_{k}}{d_{k}^{T} y_{k}}
\end{aligned}
$$

and the direction is defined by: 


$$
d_{k+1}=-g_{k+1}+\left[\frac{\mathrm{g}_{\mathrm{k}+1}^{\mathrm{T}} y_{k}}{d_{k}^{T} y_{k}}-\mathrm{t} \varpi_{k} \frac{\mathrm{g}_{\mathrm{k}+1}^{\mathrm{T}} s_{k}}{d_{k}^{T} y_{k}}-\left(1-\varpi_{k}\right) \frac{t\left\|y_{k}\right\|^{2}}{d_{k}^{T} y_{k}} \frac{\mathrm{g}_{\mathrm{k}+1}^{\mathrm{T}} d_{k}}{d_{k}^{T} y_{k}}\right] d_{k}
$$

Also we can rewrite the above equation by:

$$
d_{k+1}=-g_{k+1}+\left[\frac{\mathrm{g}_{\mathrm{k}+1}^{\mathrm{T}} y_{k}}{s_{k}^{T} y_{k}}-\mathrm{t} \varpi_{k} \frac{\mathrm{g}_{\mathrm{k}+1}^{\mathrm{T}} s_{k}}{s_{k}^{T} y_{k}}-\left(1-\varpi_{k}\right) \frac{t\left\|y_{k}\right\|^{2}}{s_{k}^{T} y_{k}} \frac{\mathrm{g}_{\mathrm{k}+1}^{\mathrm{T}} s_{k}}{s_{k}^{T} y_{k}}\right] s_{k}
$$

$\varpi_{k}$ is a scalar parameter $\left(0 \leq \varpi_{k} \leq 1\right)$.

Observe that when using exact line searches (ELS), (8) reduce to $\beta_{k}^{H S}$ and using inexact line searches (ILS), when $\varpi_{k}=1$, (8) reduce to $\beta_{k}^{D L}$ and when $\varpi_{k}=0$, (8) to $\beta_{k}^{H Z}$.

\section{CONVERGENCE ANAYLSIS OF NEW METHOD}

In this section, we will show the convergent analysis based on the inexact line search by means of Wolfe line search. We will also show that these CG-coefficients will possess sufficient descent conditions and global convergence properties. Under this inexact line search (7a) and (7b). In the following theorem; we discuss the sufficient condition:

\subsection{Sufficient descent condition}

For the sufficient descent condition, we present the following Theorem,

\section{Theorem 1}

Let $g_{k}$ and $d_{k}$ be sequences of generated methods by (2),(3) and (8), then (9) achievedand satisfy the sufficient descent property.

Proof:

multiplying (9) by quantity $\left(\frac{g_{k+1}}{\left\|g_{k+1}\right\|^{2}}\right)$ yields:

$$
\begin{aligned}
& \frac{d_{k+1}^{T} g_{k+1}}{\left\|g_{k+1}\right\|^{2}}=-1+\left[\frac{\mathrm{g}_{\mathrm{k}+1}^{\mathrm{T}} y_{k}\left(\mathrm{~s}_{\mathrm{k}}^{\mathrm{T}} \mathrm{g}_{\mathrm{k}+1}\right)}{y_{k}^{T} s_{k}\left\|g_{k+1}\right\|^{2}}-\mathrm{t} \varpi_{k} \frac{\left(\mathrm{g}_{\mathrm{k}+1}^{\mathrm{T}} s_{k}\right)^{2}}{y_{k}^{T} s_{k}\left\|g_{k+1}\right\|^{2}}-\left(1-\varpi_{k}\right) \frac{t\left\|y_{k}\right\|^{2}}{y_{k}^{T} s_{k}} \frac{\left(\mathrm{g}_{\mathrm{k}+1}^{\mathrm{T}} s_{k}\right)^{2}}{y_{k}^{T} s_{k}\left\|g_{k+1}\right\|^{2}}\right] \\
& \text { since } g_{k+1}^{T} s_{k} \leq s_{k}^{T} y_{k} \\
& \frac{d_{k+1}^{T} g_{k+1}}{\left\|g_{k+1}\right\|^{2}}+1 \leq\left[\frac{\mathrm{g}_{\mathrm{k}+1}^{\mathrm{T}} y_{k}\left(\mathrm{~s}_{\mathrm{k}}^{\mathrm{T}} y_{k}\right)}{s_{k}^{T} y_{k}\left\|g_{k+1}\right\|^{2}}-\mathrm{t} \varpi_{k} \frac{\left(\mathrm{s}_{\mathrm{k}}^{\mathrm{T}} y_{k}\right)^{2}}{s_{k}^{T} y_{k}\left\|g_{k+1}\right\|^{2}}-\left(1-\varpi_{k}\right) \frac{t\left\|y_{k}\right\|^{2}}{\left(s_{k}^{T} y_{k}\right)^{2}} \frac{\left(s_{k}^{T} y_{k}\right)^{2}}{\left\|g_{k+1}\right\|^{2}}\right] \\
& y_{k}^{T} g_{k+1} \leq\left\|y_{k}\right\| \cdot\left\|g_{k+1}\right\| \\
& \frac{d_{k+1}^{T} g_{k+1}}{\left\|g_{k+1}\right\|^{2}}+1 \leq \frac{\left\|\mathrm{y}_{\mathrm{k}}\right\|}{\left\|g_{k+1}\right\|}=\mu, \text { where } \mu>0
\end{aligned}
$$




$$
\begin{aligned}
& \frac{d_{k+1}^{T} g_{k+1}}{\left\|g_{k+1}\right\|^{2}}+1 \leq \mu \\
& d_{k+1}^{T} g_{k+1} \leq-(1-\mu)\left\|g_{k+1}\right\|^{2}
\end{aligned}
$$

\subsection{Global Convergent Properties}

To prove the global convergenceporoperty, we need the relation $s_{k}^{T} y_{k} \geq m\left\|s_{k}\right\|^{2}, \forall x, y \in R^{n}, m>0$ where $\mathrm{m}$ is constant, see [18-20]. The following assumption is needed in order to proceed with the proof of global convergence property.

\section{Assumption 1}

i) The level set $S=\left\{x: f(x) \leq f\left(x_{0}\right)\right\}$ is bounded, that is, there exists a constant $\mathrm{z}>0$, such $\|\mathrm{x}\| \leq \mathrm{z}, \forall \mathrm{x} \in \mathrm{S}$

ii) In neighborhood $\mathrm{N}$ of $\mathrm{S}, \mathrm{f}$ is continuously differentiable, and its gradient is Lipschitz

$$
\|g(x)-g(y)\| \leq L\|x-y\|, \quad \forall x, y \in N
$$

Below the assumptions (i) and (ii) on $\mathrm{f}$, we are able to deduce that there exists $\gamma>0$ such as,

$$
\begin{aligned}
& \gamma \leq\|\nabla f(x)\| \leq \bar{\gamma} \\
& \text { iii) }(g(x)-g(y))(x-y) \geq \mu\|x-y\|^{2}, \quad \forall \mathrm{x}, \mathrm{y} \in \mathrm{S}, \mu>0
\end{aligned}
$$

Under this Assumption, the following lemma is obtained, which was proved by [11]

\section{Lemma 1}

Assume that Assumption-1 hold and suppose that for any CG-method $d_{k+1}$ is a descent direction and the step size ${ }^{\alpha}$ is achieved by (7a,7b). If,

$$
\sum_{k \geq 1} \frac{1}{\left\|d_{k+1}\right\|^{2}}=\infty
$$

Then,

$$
\underset{k \rightarrow \infty}{\operatorname{Lim}}\left(\inf \left\|g_{k}\right\|\right)=0
$$

\section{Theorem 2}

Suppose that Assumption-1 is true ,consider the new algorithm with $\beta_{k}^{\text {new }}$,then the algorithm has

$$
\underset{\mathrm{k} \rightarrow \infty}{\operatorname{Lim}} \inf \left\|\mathrm{g}_{\mathrm{k}}\right\|=0
$$

Proof:

$$
\left\|d_{k+1}\right\|=\left\|-g_{k+1}+\left[\frac{\mathrm{g}_{\mathrm{k}+1}^{\mathrm{T}} y_{k}}{y_{k}^{T} s_{k}}-\mathrm{t} \varpi_{k} \frac{\mathrm{g}_{\mathrm{k}+1}^{\mathrm{T}} s_{k}}{y_{k}^{T} s_{k}}-\left(1-\varpi_{k}\right) \frac{t\left\|y_{k}\right\|^{2}}{y_{k}^{T} s_{k}} \frac{\mathrm{g}_{\mathrm{k}+1}^{\mathrm{T}} s_{k}}{y_{k}^{T} s_{k}}\right] s_{k}\right\|
$$




$$
\left\|d_{k+1}\right\| \leq\left\|g_{k+1}\right\|+\left[\frac{\mid g_{k+1}^{T} y_{k}}{y_{k}^{T} s_{k}}|+| t \varpi_{k}|| \frac{g_{k+1}^{T} s_{k}}{y_{k}^{T} s_{k}}\left|+\left(1-\varpi_{k}\right)\right| \frac{t\left\|y_{k}\right\|^{2}}{y_{k}^{T} s_{k}} \frac{g_{k+1}^{T} s_{k}}{y_{k}^{T} s_{k}} \mid\right]\left\|s_{k}\right\|
$$

Since $\mathrm{y}_{\mathrm{k}}^{\mathrm{T}} \mathrm{g}_{\mathrm{k}+1} \leq\left\|\mathrm{y}_{\mathrm{k}}\right\| \cdot\left\|\mathrm{g}_{\mathrm{k}+1}\right\|, \mathrm{s}_{\mathrm{k}}^{\mathrm{T}} \mathrm{g}_{\mathrm{k}+1} \leq \mathrm{s}_{\mathrm{k}}^{\mathrm{T}} \mathrm{y}_{\mathrm{k}}$ and $\mathrm{s}_{\mathrm{k}}^{\mathrm{T}} \mathrm{y}_{\mathrm{k}} \geq \mathrm{m}\left\|\mathrm{s}_{\mathrm{k}}\right\|^{2}$

$$
\begin{aligned}
& \left\|d_{k+1}\right\| \leq\left\|g_{k+1}\right\|+\left[\frac{\left\|g_{k+1}\right\| y_{k} \|}{m\left\|s_{k}\right\|^{2}}+\left|\mathrm{t} \varpi_{k}\right| \frac{y_{k}^{T} s_{k}}{y_{k}^{T} s}+\left(1-\varpi_{k}\right) \frac{t\left\|y_{k}\right\|^{2} y_{k}^{T} s_{k}}{\left(y_{k}^{T} s_{k}\right)^{2}}\right]\left\|s_{k}\right\| \\
& \left\|d_{k+1}\right\| \leq\left\|g_{k+1}\right\|+\left[\frac{\left\|g_{k+1}\right\|\left\|y_{k}\right\|}{m\left\|s_{k}\right\|^{2}}+\left|t \varpi_{k}\right|+\left(1-\varpi_{k}\right) \frac{t\left\|y_{k}\right\|^{2}}{m\left\|s_{k}\right\|^{2}}\right]\left\|s_{k}\right\|
\end{aligned}
$$

Let $c_{1}=\frac{\left\|g_{k+1} \mid\right\| y_{k} \|}{m\left\|s_{k}\right\|^{2}}+\left|t \varpi_{k}\right|+\left(1-\varpi_{k}\right) \frac{t\left\|y_{k}\right\|^{2}}{m\left\|s_{k}\right\|^{2}}$

$$
\begin{aligned}
& \left\|d_{k+1}\right\| \leq\left\|g_{k+1}\right\|+c_{1}\left\|s_{k}\right\|=\xi \\
& \sum_{k \geq 1} \frac{1}{\left\|d_{k+1}\right\|^{2}} \geq \frac{1}{\xi} \sum_{k \geq 1} 1=\infty
\end{aligned}
$$

\section{DERIVATION OF THE MOFIFIED QN-METHOD}

The purpose of this section is to create a new matrix which is a modified of memoryless BFGS method [21, 22] . Observe that the search directions, defined by (9) can be written by:

$$
d_{k+1}=-\mathrm{Q}_{k+1} g_{k+1}
$$

where the matrix $Q_{k+1}$ is given by:

$$
Q_{k+1}=I-\frac{s_{k} y_{k}^{T}+y_{k} s_{k}^{T}}{s_{k}^{T} y_{k}}+\mathrm{t}\left[\varpi_{k}+\left(1-\varpi_{k}\right) \frac{\left\|y_{k}\right\|^{2}}{s_{k}^{T} y_{k}}\right] \frac{s_{k} s_{k}^{T}}{s_{k}^{T} y_{k}}
$$

This matrix is considered as a modified memoryless BFGS method.

\section{Lemma 2}

If $Q_{1}$ is positive definite matrix then all matrix $Q_{k+1}$ defined in (15) is also positive definite, i.e. $z_{k}^{T} Q_{k} z_{\mathrm{k}}>0$, for any vector $z \neq 0$.

Proof:

$$
\begin{aligned}
& z_{k}^{T} Q_{k+1} z_{k}=z_{k}^{T}\left[I-\frac{y_{k} s_{k}^{T}+s_{k} y_{k}^{T}}{s_{k}^{T} y_{k}}+\mathrm{t}\left[\varpi_{k}+\left(1-\varpi_{k}\right) \frac{\left\|y_{k}\right\|^{2}}{s_{k}^{T} y_{k}}\right] \frac{s_{k} s_{k}^{T}}{s_{k}^{T} y_{k}}\right] z_{k} \\
& =z_{k}^{T} z_{k}-\frac{\left(z_{k}^{T} y_{k}\right)\left(s_{k}^{T} z_{k}\right)}{s_{k}^{T} y_{k}}+\frac{\left(z_{k}^{T} s_{k}\right)\left(y_{k}^{T} z_{k}\right)}{s_{k}^{T} y_{k}}+\mathrm{t}\left(\varpi_{k}+\left(1-\varpi_{k}\right) \frac{\left\|y_{k}\right\|^{2}}{s_{k}^{T} y_{k}}\right) \frac{\left(z_{k}^{T} s_{k}\right)^{2}}{s_{k}^{T} y_{k}}
\end{aligned}
$$




$$
=z_{k}^{T} z_{k}+\zeta_{k}, \text { where } \xi_{k}=t\left(\varpi_{k}+\left(1-\varpi_{k}\right) \frac{\left\|y_{k}\right\|^{2}}{s_{k}^{T} y_{k}} \frac{\left(s_{k}^{T} z_{k}\right)^{2}}{s_{k}^{T} y_{k}}\right.
$$

Since $z_{k}^{T} z_{k}, \xi_{k}$ are greaert than zero. Then proof is complete.

\section{Theorem 3}

The matrix $Q_{k+1}$ defined by (15) achieved the following QN-condition (i,e $Q_{k+1} \mathrm{y}_{\mathrm{k}}=\rho_{k} s_{k}$ )

\section{Proof:}

$$
\begin{aligned}
& \text { Multiply (15) by } y_{k} \text { we get : } \\
& Q_{k+1} y_{k}=\left[I-\frac{\left.y_{k} s_{k}^{T}+s_{k} y_{k}^{T}\right)}{s_{k}^{T} y_{k}}+\mathrm{t}\left(\varpi_{k}+\left(1-\varpi_{k}\right) \frac{\left\|y_{k}\right\|^{2}}{s_{k}^{T} y_{k}}\right) \frac{s_{k} s_{k}^{T}}{s_{k}^{T} y_{k}}\right] y_{k} \\
& =y_{k}-\frac{y_{k}\left(s_{k}^{T} y_{k}\right)}{s_{k}^{T} y_{k}}-\frac{s_{k}\left(y_{k}^{T} y_{k}\right)}{s_{k}^{T} y_{k}}+\mathrm{t} \varpi_{k} \frac{s_{k}\left(s_{k}^{T} y_{k}\right)}{s_{k}^{T} y_{k}}+t\left(1-\varpi_{k}\right) \frac{\left\|y_{k}\right\|^{2}}{s_{k}^{T} y_{k}} \frac{s_{k}\left(s_{k}^{T} y_{k}\right)}{s_{k}^{T} y_{k}} \\
& =s_{k} \frac{\left\|y_{k}\right\|^{2}}{s_{k}^{T} y_{k}}+t \varpi_{k} s_{k}+t\left(1-\varpi_{k}\right) \frac{\left\|y_{k}\right\|^{2}}{s_{k}^{T} y_{k}} s_{k} \\
& {\left[\frac{\left\|y_{k}\right\|^{2}}{s_{k}^{T} y_{k}}+t \varpi_{k} s_{k}+t\left(1-\varpi_{k}\right) \frac{\left\|y_{k}\right\|^{2}}{s_{k}^{T} y_{k}}\right] s_{k}} \\
& \quad\left[\frac{\left\|y_{k}\right\|^{2}}{s_{k}^{T} y_{k}}+t \varpi_{k} s_{k}+t\left(1-\varpi_{k}\right) \frac{\left\|y_{k}\right\|^{2}}{s_{k}^{T} y_{k}}\right]=\rho_{k} \\
& Q_{k+1} \mathrm{y}_{\mathrm{k}}=\rho_{k} s_{k}
\end{aligned}
$$

\section{RESULTS AND DISCUSSION}

In this section we present the computational performance of a Fortran implementation of the HYBRID algorithm (New1)on a set of(750) unconstrained optimization test problems. The test problems are the unconstrained problems in the CUTE [7] library, along with other large-scale optimization problems presented in $[23,24]$. We selected (75) large-scale unconstrained optimization problems in extended or generalized form. Each problem is tested (10) times for a gradually increasing number of variables: $\mathrm{n}=1000,2000,10000$, To demonstrate the efficiency of the new algorithm, we used the Dolan and more' method. The curve of the curve to the top indicates the new method better than the rest of the previous methods. All algorithms implement the Wolfe line search conditions with $\sigma=0.9$ and $\delta=0.001[25,26]$, the same stopping criteria when $\left\|g_{k}\right\| \leq 10^{-5}$.

In the first set of numerical experiments we compare the new method with DL and HZ method.. By calculating the number of the function evaluations (NOF), the frequency of the method (NOI) and the time required to implement the method (CPU), The new algorithm was compared to similar algorithms :

a. A new proposed method (New) define by (8)

b. DLconjugate gradient methoddefineby (4)

c. HZ conjugate gradient method (6)

Our demonstrated results are shown in Figures 1-6. We used the Dolan and more' method [27, 28]. Figures 1-3, list the performance of the above methods relative to iterations number, the number of gradient evaluations and the CPU time, respectively. The second set of numerical experiments refers to the 
comparisons of new method (15) with memoryless BFGS method. Figures 4-6, list the performance of the above methods. To demonstrate the efficiency of the new algorithm.

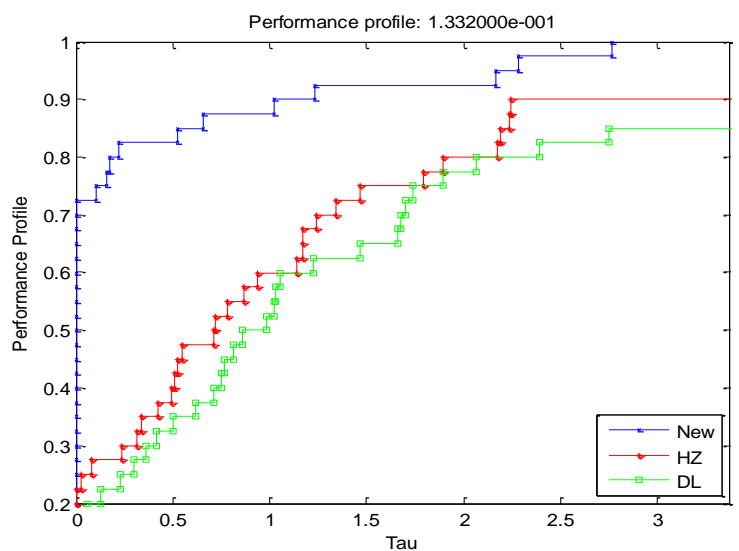

Figure 1. Performance profiles based on function evaluation

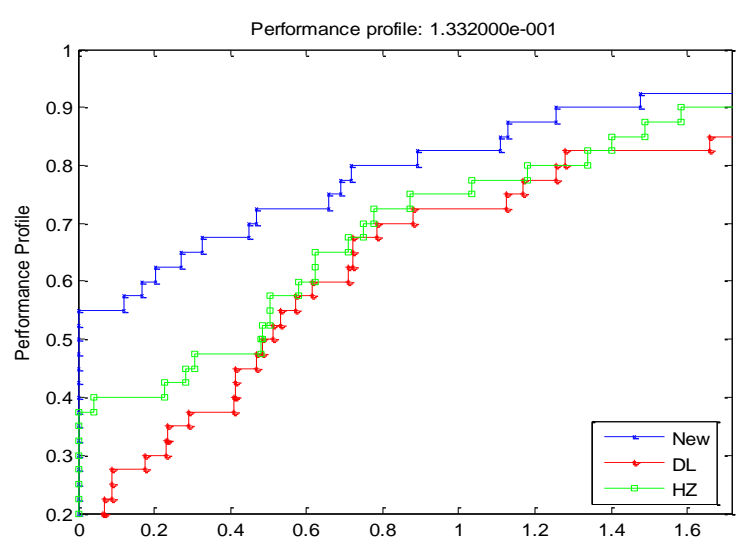

Figure 2. Performance profiles based on number of iterations

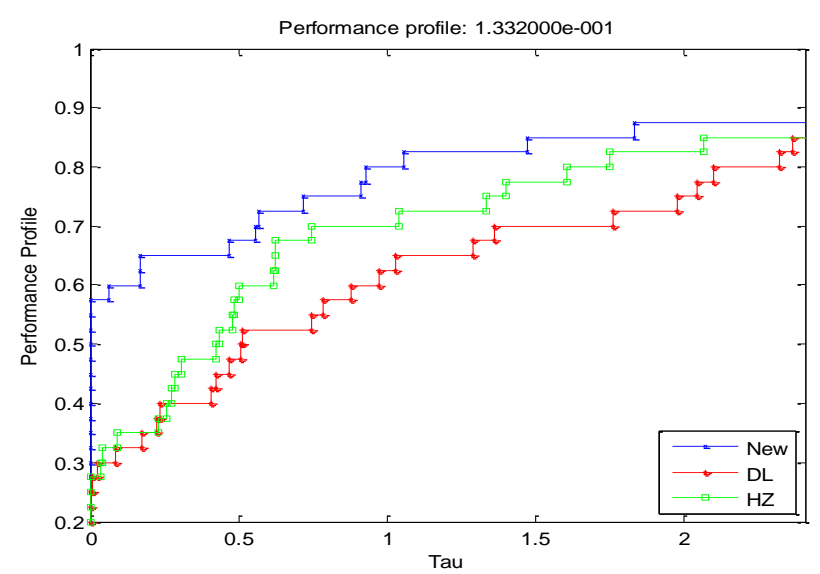

Figure3. Performance profiles based on CPU time

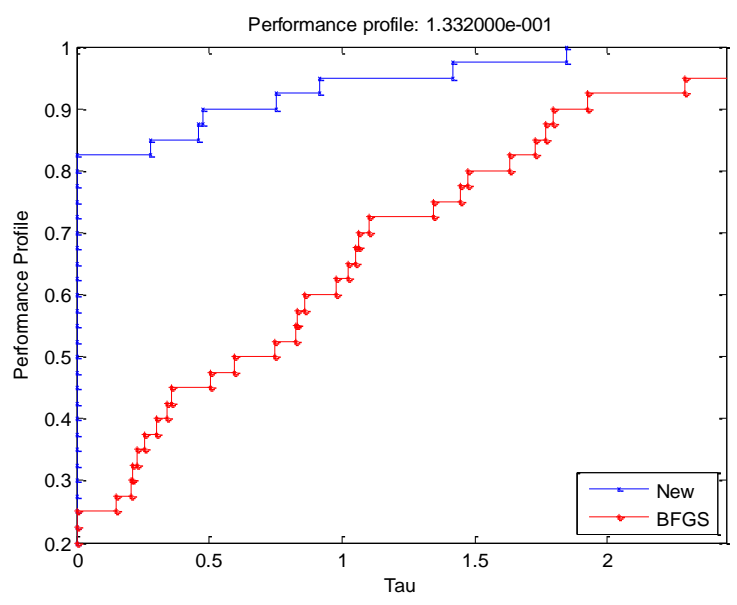

Figure 4. Performance profiles based on CPU time

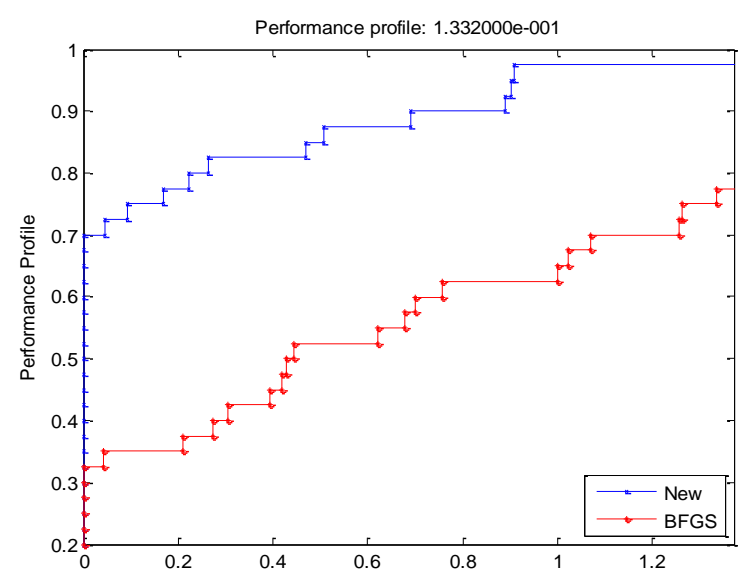

Figure 5. Performance profiles based on number of iterations 


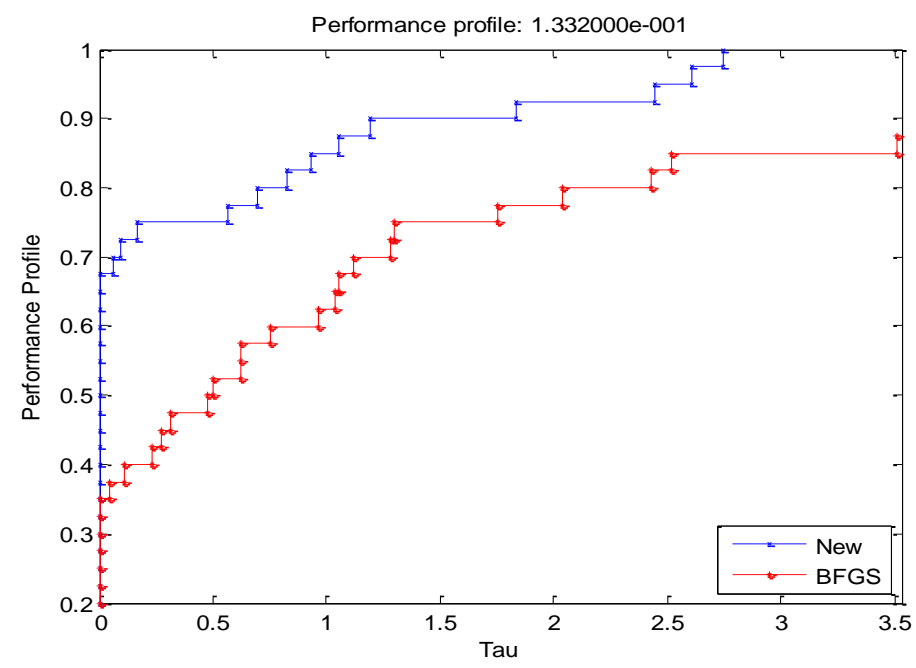

Figure 6. Performance profiles based on function evaluation

\section{CONCLUSIONS}

We suggested a linear combination between HZ and DL method and get a new proposed CGmethod namely (2), (3) and (8) under some condition, we prove that our method is global convergent for convex functions. Also, we drive a new matrix defined in (15) and we have proved that its positive definiteness is achieved and satifythe QN-condition. Numerical results showed that our suggested method gives an effective numerical result in practically.

\section{ACKNOWLEDGEMENTS}

The research is supported by College of Computer Sciences and Mathematics, University of Mosul, Republic of Iraq.

\section{REFERENCES}

[1] M.R. Hestense andE.1. Stiefel, "Methods of conjugate gradients for solving linear system," J. Research Nat.Bur. Standards, vol. 49, pp. 409-436, 1952.

[2] R. Fletcher and C.Reeves, "Functionminimization by conjugate gradients," Comput. J., vol. 7, pp.149-154, 1964.

[3] E.Polak,andG Ribiere, "Note sur la convergence de methods de directions conjugate'e," Rev. Francaise Informat.Recherché Ope'rtionelle, vol. 3, pp. 35-43, 1969.

[4] B.T. Polaak, "The conjugate gradient method in extreme problems, "USSR comp. Math. and Math Phys., vol. 9, pp. 94-112, 1969.

[5] Y. H. Dai and Y. Yuan, "A nonlinear conjugate gradient method with a strong global convergence property," SIAM J. on Optim., pp. 177-18, 1999.

[6] Y. H. Dai and L.Z. Liao, "New conjugacy conditions and related nonlinear conjugategradient methods," Appl. Math. Optim., vol. 43, pp. 87-101, 2001.

[7] W.W Hager and Zhang,"Anew conjugate gradient method with guaranteed descent and an efficient Line search ,"SIAM J.Optim., vol. 16, pp. 170-192, 2005.

[8] W.W Hager and Zhang,"A Survey of nonlinear conjugate gradient methods, "Pacific J. Optim., vol. 2, pp. 35-58, 2006.

[9] E. T. Hamed, H. I. Ahmed,and A. Y. Al-Bayati, "A New Hybrid Algorithm for Convex Nonlinear Unconstrained Optimization," Journal of Applied Mathematics, vol. 2019,. https://doi.org/10.1155/2019/8728196, 2019.

[10] M. K. Dauda, M.Mamat, M. A. Mohamed and N. S. A. Hamzah, "Hybrid conjugate gradient parameter for solving symmetric systems of nonlinear equations," Indonesian Journal of Electrical Engineering and Computer Science (IJEECS), vol. 16, no. 1, pp. 539-543. DOI: 10.11591/ijeecs.v16.i1.pp539-543, 2019.

[11] E.T.Hamed,R.Z. Al-Kawaz and A.Y.Al- Bayati, "New investigation for the Liu-Story scaled conjugate gradient methodfor nonlinear optimization," Hindawi J. Math, vol. 2020,.https://doi.org/10.1155/2020/3615208,2020.

[12] H.I. Ahmed, R.Z.Al-Kawaz and A.Y. Al- Bayati, "Spectral three-term constrained conjugate gradient algorithm for function minimizations," Hindawi J. Appl. Math., vol 2019,.https://doi.org/10.1155/2019/6378368, 2019.

[13] E.T.Hamed, H.I.Ahmed, H. Y. Najm, "Global Convergence of Conjugate Gradient Method inUnconstrainedOptimizationProblems, "International Conference of Mathematical Sciences (ICMS 2018) AIP 
Conf.Proc. 2086, 030029-1-030029-4; https://doi.org/10.1063/1.5095114,Published by AIP Publishing. 978-073541816-5.

[14] B. A.Hassan, H. O.Dahawi and A. S. Younus, "A new kind of parameter conjugate gradient for unconstrained optimization," Indonesian Journal of Electrical Engineering and Computer Science (IJEECS), vol. 17, no. 1, pp. 404-411, 2019.

[15] B. A Hassan, Z. M. Abdullah, H. N. Jabbar, "A descent extension of the Dai - Yuan conjugate gradient technique," "Indonesian Journal of Electrical Engineering and Computer Science (IJEECS), vol. 16, no. 2, pp. 661668. DOI: 10.11591/ijeecs.v16.i2.pp661-668, November 2019.

[16] C. Ahmed and B. Taher, "A new modification nonlinear conjugate gradient method with strong wolf-powell line search," Indonesian Journal of Electrical Engineering and Computer Science (IJEECS), vol. 18, no. 1, pp. 525-532, DOI:10.11591/ijeecs.v18.i1.pp525-532, April 2020.

[17] N. S. Mohamed, M. Mamat, M.Rivaie, S. M.Shaharudin, "A new hybrid coefficient of conjugate gradient method, "Indonesian Journal of Electrical Engineering and Computer Science (IJEECS), vol. 18, no. 3, June 2020, pp. 1454-1463, DOI: 10.11591/ijeecs.v18.i3.pp1454-1463, 2020.

[18] Y.H. Dai, Han J.Y., Liu, G.H., Sun, D.F., Yin, .X. and Yuan, Y., "Convergence properties of Nonlinear conjugate gradient methods," SIAM Jurnal on Optimization, vol. 10, pp. 348-358, 1999.

[19] R. Ghanbari., S .Babaie-kafaki, "An A dative Hager-Zhang Conjugate Gradient Method, "Faculty of sciences Mathematics, pp. 3715-3723, 2016.

[20] Yabe, H., and Takano, M., "Global convergence properties of new nonlinear conjugate gradientmethods for unconstrained optimization," Computational Optimization and Application, vol. 28, pp. 203-225, 2004.

[21] J.M. Perry, "A class of conjugate gradient algorithms with a two-step variable-metric Discussion paper 269, Center forMathematical Studies in Economics and Management Science,” Northwestern University, EvanstonIllinois, 1977.

[22] D.F. Shanno, "On the convergence of anew conjugate gradient algorithm," SIAMJ. Number .Anal, pp. 1247-1257, 1978.

[23] N. Andrei, "An unconstrained optimization test functions collection, "Advanced Modeling and Optimization, the Electronic International Journal, voL. 10, no. L, pp.147-161, 2008.

[24] N. Andrei, "Open problems in nonlinear conjugate gradient algorithms for unconstrained optimization" Bulletin of the Malaysian Mathematical Science Society. Second series, vol. 34, pp. 319-330, 2011.

[25] H.I. Ahmed, E.T.Hamed and Hamsa Th. Saeed Chilmeran, "A Modified Bat-Algorithm with Conjugate Gradient Method for Global Optimization," Hindawi International Journal of Mathematics and Mathematical Sciences, Vol. 2020, Article ID 4795793, 14 pages ,https://doi.org/10.1155/2020/4795793, 2020.

[26] R. Z. Al-Kawaz.,A. Y. Al-Bayati, M. S. Jameel, "Interaction between updated FR-CG algorithms with the optimal Cuckoo algorithm, "Indonesian Journal of Electrical Engineering and Computer Science (IJEECS), vol. 19, no. 3, 2020.

[27] A. A., Al-Arbo1, and R. Z. Al-Kawaz, "Implementation of a combined new optimal cuckoo algorithm with a gray wolf algorithm to solve unconstrained optimization nonlinear problems." Indonesian Journal of Electrical Engineering and Computer Science (IJEECS), vol. 19, no. 3, pp. 1582-1589, 2020.

[28] E. D. Dolan and J. J. Mor'e, "Benchmarking optimization software with performance profiles," Mathematical Programming, vol. 91, no. 2, pp. 201-213, 2002. 